\title{
Experimental study of temperature gradient in track slab under outdoor conditions in Chengdu area
}

\author{
Zhao Pingrui $\cdot$ Liu Xueyi $\cdot$ Liu Guan
}

Received: 22 November 2013/Revised: 10 April 2014/Accepted: 11 April 2014/Published online: 16 May 2014

(C) The Author(s) 2014. This article is published with open access at Springerlink.com

\begin{abstract}
Temperature is one of the important loads for designing slab track. The characteristic of slab track temperature varies greatly with different regional climates. In this work, a bi-block slab track model was built under outdoor conditions in Chengdu area; the statistical characteristic of temperature gradient in track slab and the relationship between temperature gradient and surface air temperature were tested and analyzed. The results show that the track slab temperature gradient will vary periodically according to the surface air temperature, and show a clear nonlinearity along the height direction. The temperature gradient distribution is extremely uneven: the temperature gradient in the top part of the track slab is larger than that in the bottom part; the most frequently occurring temperature gradient of the track slab is around $-3.5^{\circ} \mathrm{C} / \mathrm{m}$ and more than $75 \%$ locates in the level -10 to $10{ }^{\circ} \mathrm{C} / \mathrm{m}$; concrete with a relatively good heat exchange condition with the surrounding air has a narrower band distribution. In addition, the frequency distribution histogram should exclude the time zone from 00:00 to 06:00 because there is almost no traffic in this period. The amplitude of track slab temperature variation is obviously lower than that of the air temperature variation, and the former is approximately linear with the latter.
\end{abstract}

Keywords Slab track - Track slab - Temperature gradient $\cdot$ Temperature field $\cdot$ Surface air temperature

With the rapid development of high-speed railway, as a new type of track structure, slab track was widely used in

Z. Pingrui · L. Xueyi $\cdot$ L. Guan $(\bowtie)$

MOE Key Laboratory of High-speed Railway Engineering,

Southwest Jiaotong University, Chengdu 610031, China

e-mail: 75994776@qq.com
China, especially for the lines for which the maximum operation speed exceeds $300 \mathrm{~km} / \mathrm{h}$. Compared to the traditional ballasted track, concrete or asphalt material was used in slab track instead of discrete ballast which will deform easily due to the flow and wear under high-speed train-induced vibration. This can give the slab track a guaranteed ability to maintain long-term and high-precision track geometry. At present, most of slab tracks in China's high-speed railway are reinforced concrete structure-including CRTS I, CRTS II, and CRTS III slab track; and CRTS I and CRTS II bi-block slab track [1].

Temperature in slab track will change with the environmental temperature, especially for the top layer of the slab track system-track slab. Due to the thermal expansion and contraction of the concrete, the temperature variation will lead to thermal stress in slab track. Therefore, thermal stress is a very important factor to design the slab track. Normally, the thermal load can be divided into three parts (Fig. 1): the overall sectional temperature change, temperature gradient, and self-constrained temperature, which will cause expansion stress, warping stress, and inner stress, respectively [2]. For the continuous slab track, the expansion stress will control the design; while for the unit slab track, the warping stress can be the control factor of the design [3].

It is convenient to measure and make statistics of the environmental temperature. If there is a relationship between the temperature in slab track and the ambient air temperature, the statistical characteristic of the slab track temperature can be extracted from the statistical characteristic of the air temperature. In China slab track design, the maximum temperature gradient for design is set from pavement design [4]. Many researchers have conducted tests to measure the temperature field in concrete pavement $[5,6]$. However, because of the large dimension of the 

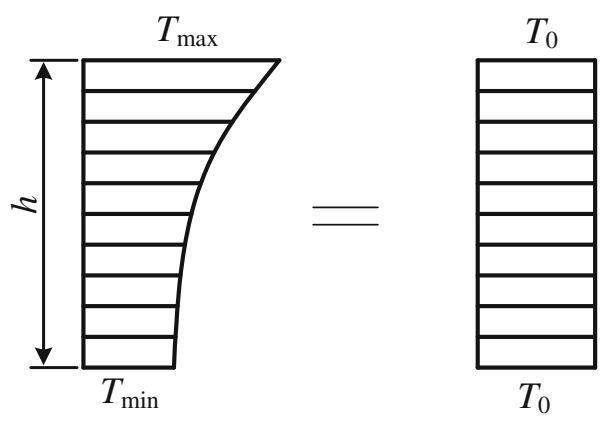

Fig. 1 Typical temperature distribution in track slab

pavement and different heat exchange conditions of pavements, the data measured from concrete pavement cannot be used directly for design of slab track. Slab track is a structure that bears long-term temperature load and repeated train load [7]. In order to study the fatigue performance of the slab track, we must take into account the coupling action of the train load and temperature load $[8$, 9]. The maximum temperature value cannot reflect the fatigue performance of the slab track completely. This paper will focus on the test of temperature field in slab track to establish the connection between slab track temperature gradient and air temperature.

\section{Test plan}

The temperature change in track slab is related to the sun heat radiation and cooling condition [10]. According to the structural dimension and characteristic of the CRTS I biblock slab track, the slab was selected. A test was conducted from the end of May to the end of July, covering a period of two months. In the experiment, platinum resistance temperature sensors were used to capture the temperature of various kinds of track structure outdoors. The
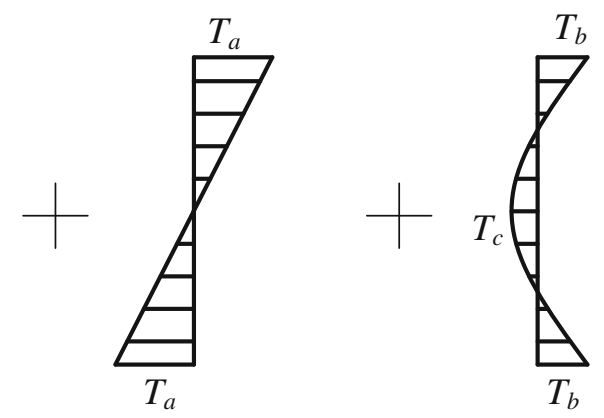

temperature sensors and the track slab for this test are shown in Fig. 2.

Ignoring the local influence of the bi-block sleeper, a track slab model with a dimension of $1 \mathrm{~m} \times 1 \mathrm{~m} \times 0.3 \mathrm{~m}$ was designed and constructed. At the middle, edge, and corner parts of the track slab (see Fig. 3a), there is one test section. At each of the test section three temperature sensors with a $100 \mathrm{~mm}$ distance were set (Fig. 3b). Above the track slab ( $2 \mathrm{~cm}$ above the surface) there is one sensor to measure the surface air temperature. Totally 10 temperature sensors are placed.

Because of the poor heat conductivity of the concrete [11], there will be differences between each sensor's data at the same section. We define the average of the data from the three sensors in the same section as the overall sectional temperature, and use the temperature difference between sensors at two different sections to calculate the temperature gradient.

The DH5975 temperature measuring system was used to collect and record the slab track temperature and surface air temperature automatically. The collection interval was $30 \mathrm{~min}$. But for the first 7 days, the interval was set to $15 \mathrm{~min}$ to reflect the influence of the cement hydration [12].
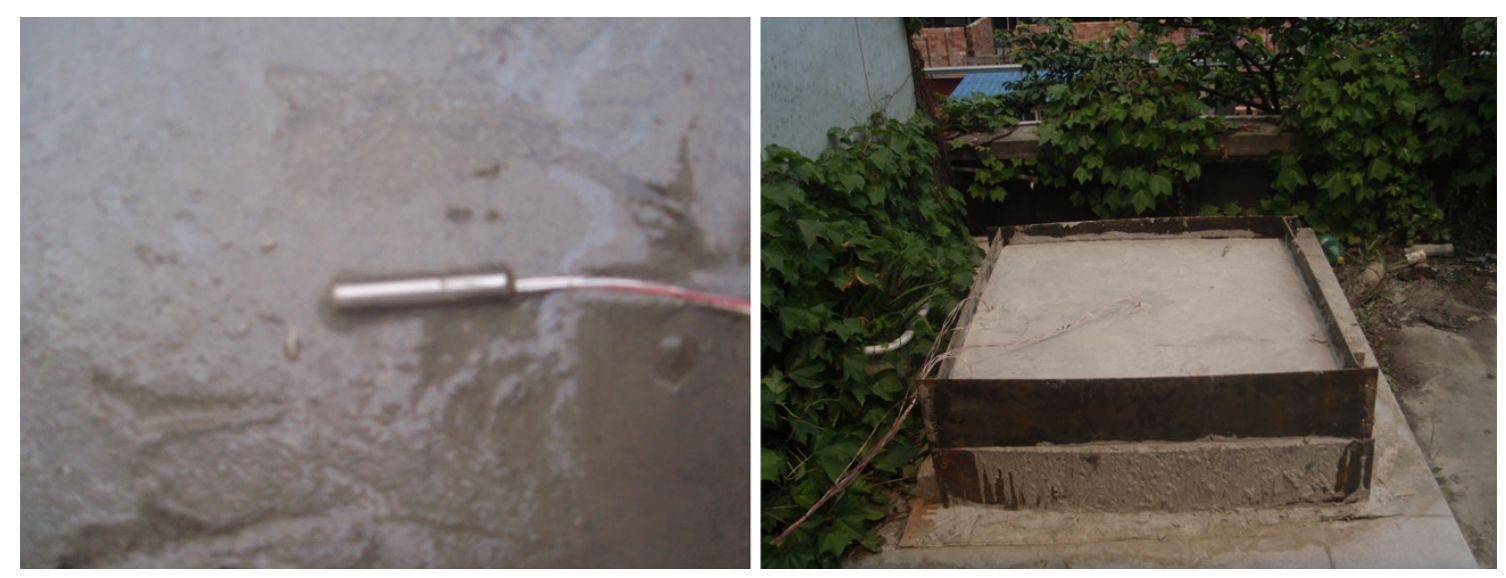

Fig. 2 The temperature sensors and the track slab for this test 


\section{Time history of overall sectional temperature change in track slab}

Taking the average of measurements from the three sensors in each section as the overall sectional temperature in track

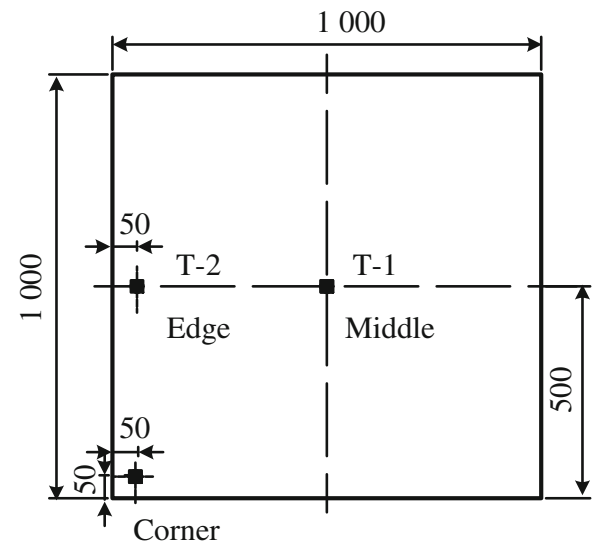

(a) Top view slab, the relationship between the sectional temperature and the surface air temperature is shown in Fig. 4.

The varying tendency of the temperature at different parts of the track slab is similar, and the moment of reaching their extreme value is almost the same. At

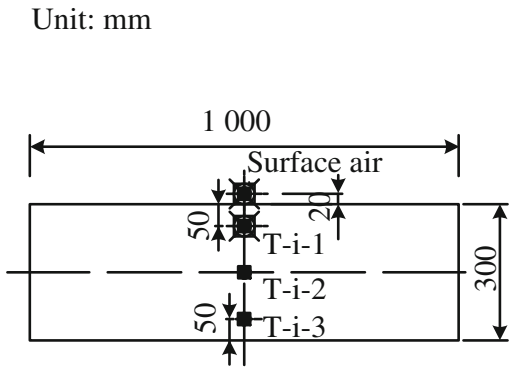

(b) Side view

Fig. 3 Schematic arrangement of the temperature field test

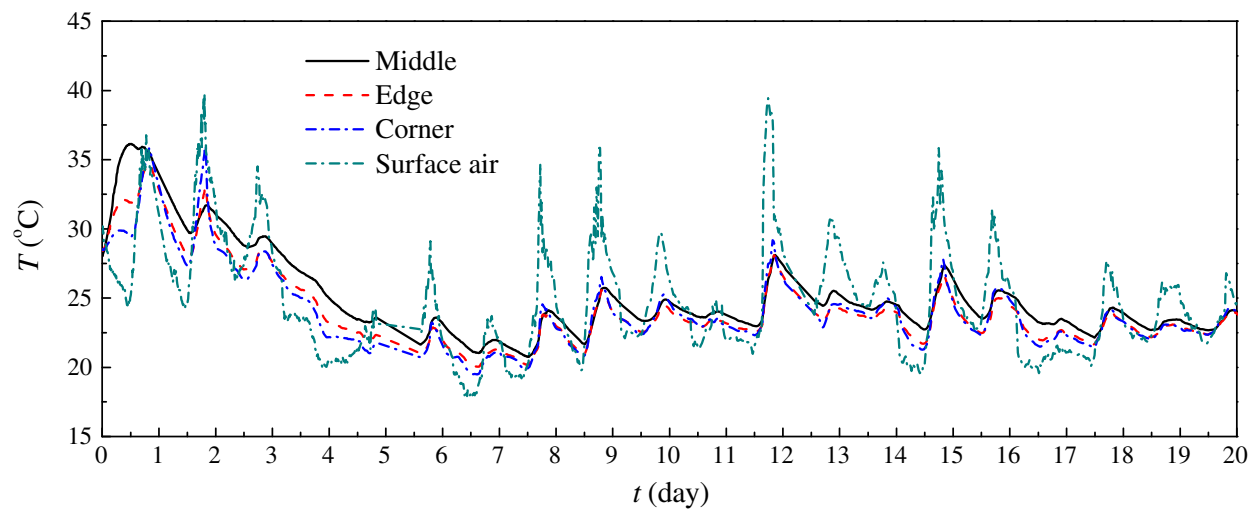

(a) 0 to 20 days

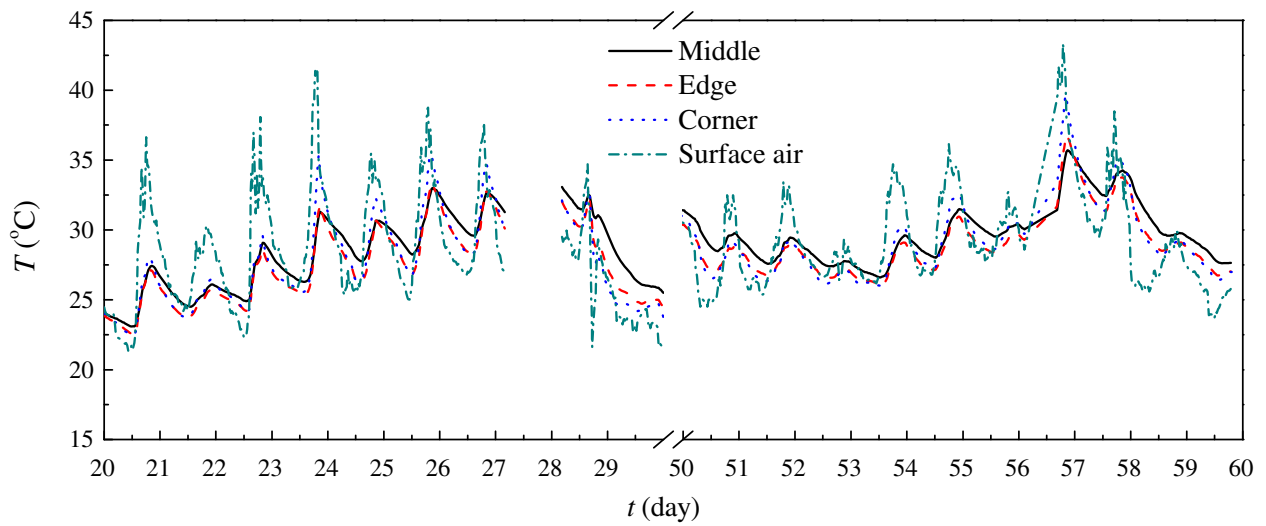

(b) 20 to 60 days

Fig. 4 Time history of track slab temperature and surface air temperature 


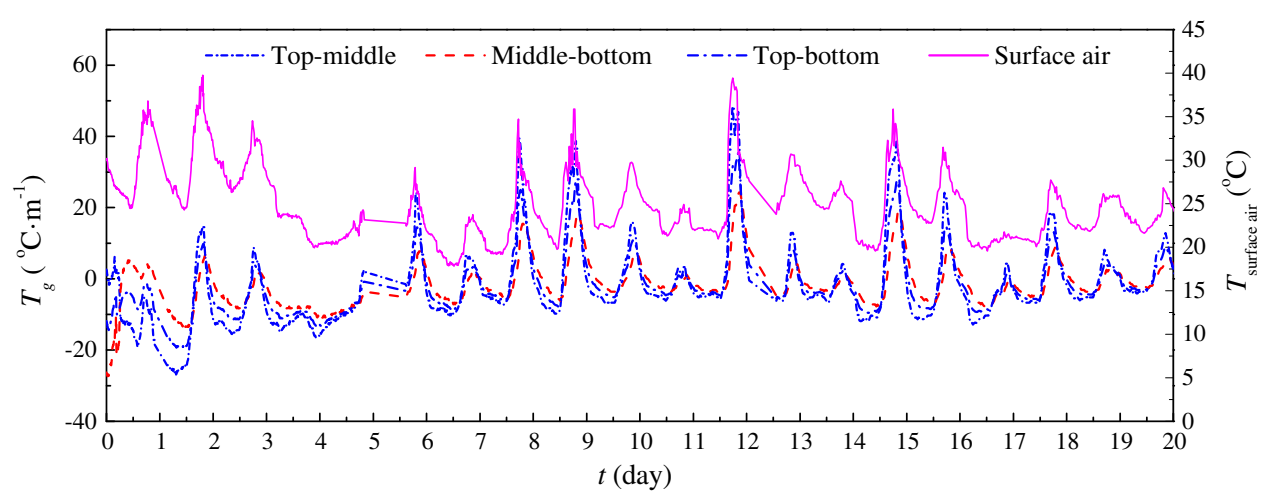

(a) 0 to 20 days

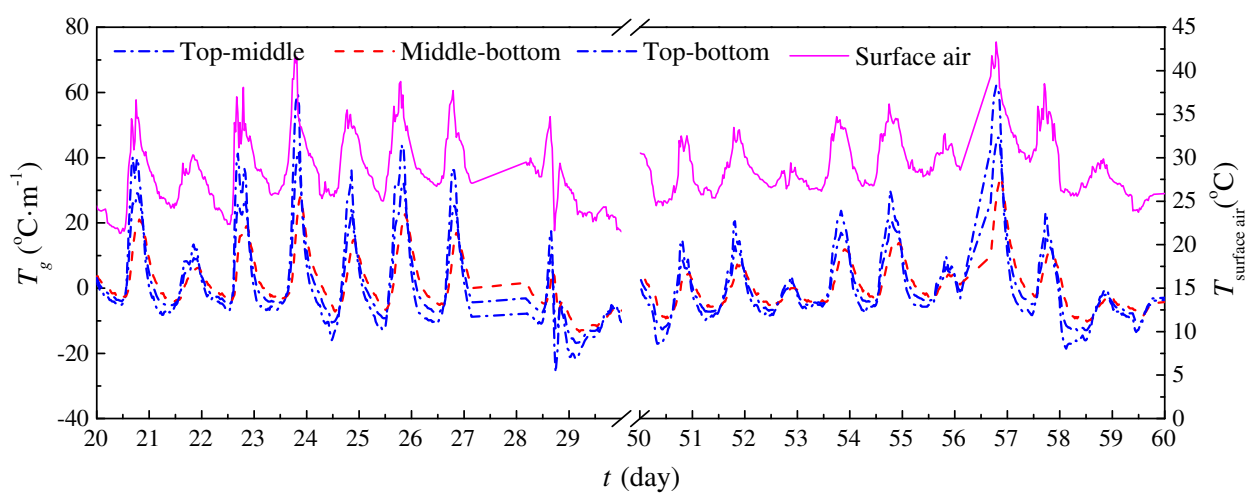

(b) 20 to 60 days

Fig. 5 Time history of track slab temperature gradient and surface air temperature (middle part)

different parts of the concrete, the heat exchange conditions are different because of the different contact areas with the surrounding air, causing a difference in temperature measurements. When the temperature rises during the daytime, the temperature increment at the corner and edge parts is a bit larger than the one at the middle part, and vice versa. The amplitude of temperature changes is in a descending order from the corner, edge to middle.

The track slab temperature varies periodically with the air temperature-rising during the daytime and dropping at nighttime. The higher the air temperature, the higher the track slab temperature. The time for track slab temperature to reach its extreme value is $2 \mathrm{~h}$ later than that for the air temperature for a $30-\mathrm{cm}$-thick track slab in Chengdu area.

\section{The time history of temperature gradient in track slab}

Using the acquired data from the three temperature sensors in the same test section of the track slab, we can calculate the temperature gradient of the track slab through the following formula:

$T_{\mathrm{g}}=\left(T_{i}-T_{j}\right) /\left(H_{i}-H_{j}\right)$, where $T_{\mathrm{g}}$ is temperature gradient $\left({ }^{\circ} \mathrm{C} / \mathrm{m}\right) ; T_{i}$ and $T_{j}$ are temperatures measured by two sensors at the top, middle, or bottom layer of the track slab $\left({ }^{\circ} \mathrm{C}\right)$; and $H_{i}$ and $H_{j}$ are the heights of the two sensors (m).

The time history of temperature gradient at the middle part of the track slab is shown in Fig. 5. In order to facilitate comparison, the air temperature time history is also shown in the figure (the purple line). The top-middle, middle-bottom, and top-bottom represent the temperature gradients between top and middle layers, middle and bottom layers, and top and bottom layers of the concrete, respectively.

As can be seen in Fig. 5, the temperature gradient in track slab changes almost simultaneously with the surface air temperature. The temperature gradient amplitude goes high when the surface air temperature rises. The temperature gradient calculated using the top and middle sensors is clearly larger than that calculated using the middle and bottom sensors, which shows a nonlinear distribution along the height direction. The temperature gradient calculated using the top and bottom sensors is located between the above two. In designing the slab track, the nonlinear part is generally ignored and it is assumed that there is a linear distribution along the whole section. The nonlinear part will cause inner stress within the section. 


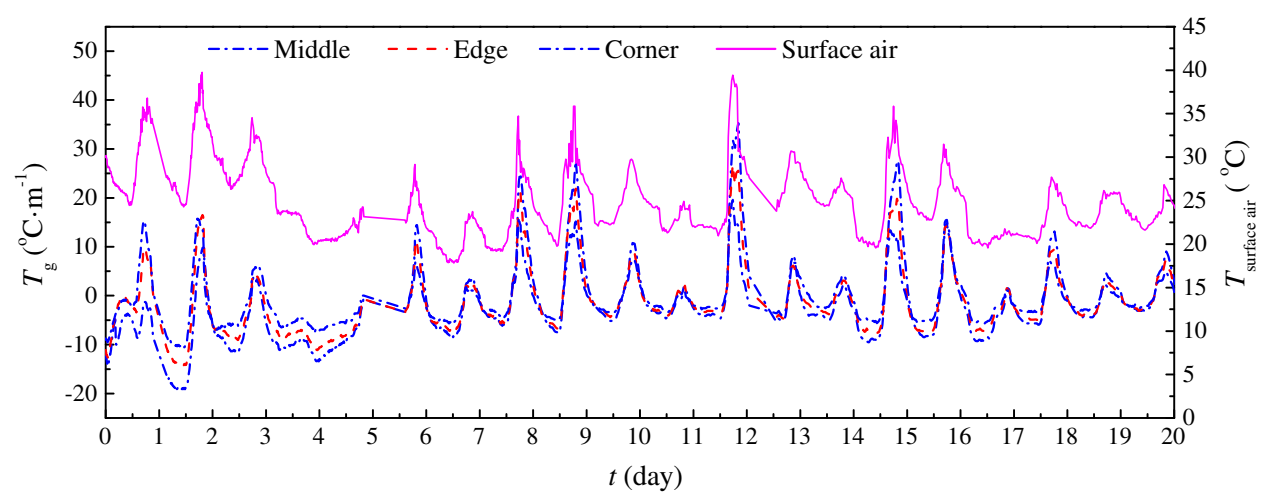

(a) 0 to 20 days

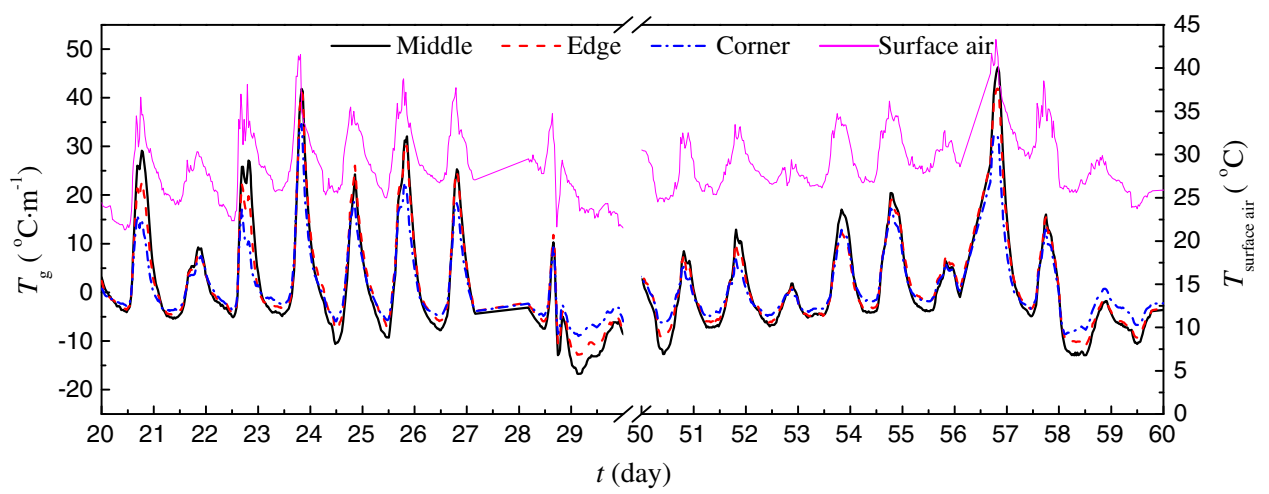

(b) 20 to 60 days

Fig. 6 Time history of track slab temperature gradient and surface air temperature (different part)

During the cement hydration phase, due to the hydration heat, the temperature at the bottom and middle layer of track slab is higher than that at the top, where heat can radiate to the outside easily, causing a large negative temperature gradient of several days.

Figure 6 shows the time history of the temperature gradients at different parts of the track slab, where the temperature gradients are calculated from the top and bottom sensors. The total trend of the temperature gradient at different locations of the track slab is the same as the surface air temperature simultaneously. Because of the different heat exchange condition with surface air, the temperature gradient at the middle part is larger than that at the edge, and both larger than that at the corner. During the hydration phase, a verse discipline can be found. During the design of slab track, the temperature gradient from the middle part should be selected as the design parameter, which can guarantee a safety design of slab track.

\section{The distribution of temperature gradient in track slab}

Excluding the first 7 days affected by hydration heat, a frequency account analysis was carried out using the time history of the track slab temperature gradient, and the frequency distribution histogram is obtained as shown in Fig. 7 (top row, from left to right is for the middle part, edge part, and corner part, respectively), where the ordinate $p$ denotes the proportion of the temperature distribution in these tested days. The temperature gradient ranges from -20 to $50{ }^{\circ} \mathrm{C} / \mathrm{m}$, but the distribution is extremely uneven. The most frequently occurring temperature gradient of the track slab is around $-3.5^{\circ} \mathrm{C} / \mathrm{m}$. Compared with the middle part, the corner part of the track slab has a narrower band distribution. This phenomenon should be attributed to the three directions of heat exchange with the surrounding air, while at the edge only two directions, and at the middle just one direction.

In top row of Fig. 7, all the data throughout the whole day are used, but in real operation, the period from midnight till 4 o'clock is the so-called vertical "window" time, when all the high-speed trains will stop for the daily maintenance of engineering structures. Therefore, when we do the statistical analysis for the fatigue analysis under the coupling action of train load and temperature load, the "window" time should be excluded. Also in the present operation, after the "window" time till 6 o'clock, only a few track inspection vehicles will run, so the statistics should exclude the data from 00:00 to 06:00. The statistical 

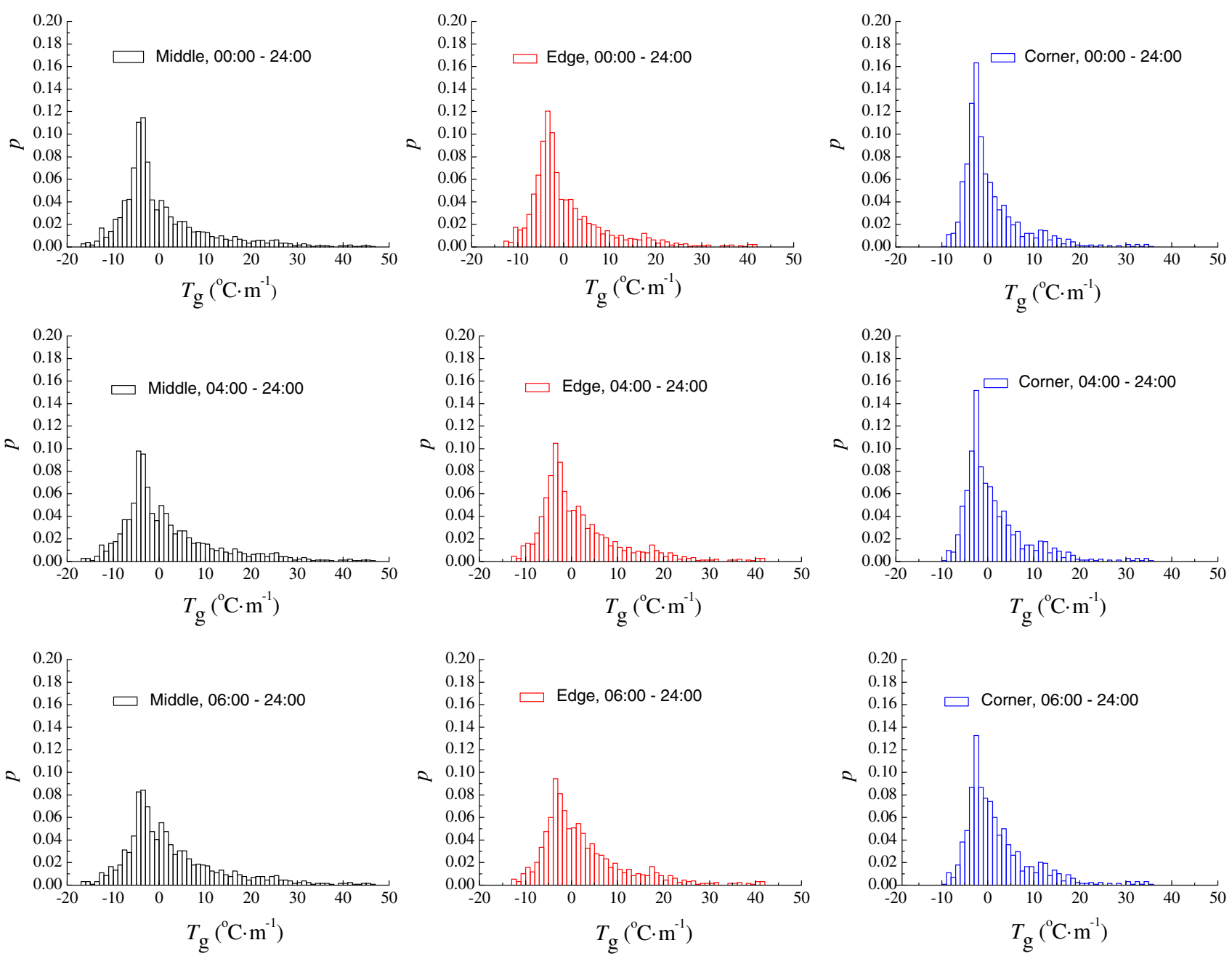

Fig. 7 Track slab temperature gradient distribution

distribution of temperature gradient in track slab using different time zone data is shown in Fig. 7 (middle row is for time zone $[4,24]$, and bottom row is for time zone [6,24]). 00:00 to 06:00 is the coldest time zone of a day, when concrete track slab is in a cooling stage that shows negative temperature gradients. It will decrease the probability of the most frequently occurring negative temperature gradient if data are excluded in this time zone. The frequency distribution histogram using the data excluding the time zone from 00:00 to 06:00 should be used, or adjusted according to the real "window" time when we do the coupling fatigue analysis of track slab under train load and temperature gradient.

Using $10{ }^{\circ} \mathrm{C} / \mathrm{m}$ as step, the percentage of different levels of temperature gradient is calculated and shown in Table 1. The most frequently occurring temperature gradient appears in -10 to $0{ }^{\circ} \mathrm{C} / \mathrm{m}, 57.9 \%$ for the middle part, $59.6 \%$ for the edge part, and $63.1 \%$ for the corner. The second frequently occurring temperature gradient is in level $0-10{ }^{\circ} \mathrm{C} / \mathrm{m}$, with the percentage of $22.7 \%, 25.4 \%$, and $27.4 \%$ for the middle, edge, and corner, respectively. Little differences exist among the different parts. When checking the fatigue of the track slab, the data acquired from the middle part of the track slab from the safety viewpoint are available. Taking account of the "window" time and the low traffic operation after maintenance work, the percentage of level -10 to $0{ }^{\circ} \mathrm{C} / \mathrm{m}$ drops to $50.6 \%$ and $45.9 \%$, and the percentage of level $0-10{ }^{\circ} \mathrm{C} / \mathrm{m}$ rises to $27.3 \%$ and $30.5 \%$ accordingly. More than $80 \%$ of the temperature gradient is between -10 and $10{ }^{\circ} \mathrm{C} / \mathrm{m}$ throughout the whole day. When the coupling action with train load is considered as an effect factor, there is still more than $75 \%$ period located in the level from -10 to $10{ }^{\circ} \mathrm{C} / \mathrm{m}$.

\section{Relationship between track slab temperature amplitude and air temperature}

Figure 8 shows the amplitude of daily temperature variation. The highest amplitude of the surface air temperature 
Table 1 Percentage of different levels of temperature gradient $(\%)$

\begin{tabular}{|c|c|c|c|c|c|c|c|c|}
\hline Time zone & Level of temperature gradient $\left({ }^{\circ} \mathrm{C} / \mathrm{m}\right)$ & -20 to -10 & -10 to 0 & $0-10$ & $10-20$ & $20-30$ & $30-40$ & $40-50$ \\
\hline \multirow[t]{3}{*}{ 00:00-24:00 } & Middle & 5.3 & 57.9 & 22.7 & 7.8 & 4.3 & 1.2 & 0.7 \\
\hline & Edge & 2.7 & 59.6 & 25.4 & 8.3 & 2.8 & 0.9 & 0.5 \\
\hline & Corner & 0.0 & 63.1 & 27.4 & 7.8 & 0.9 & 0.9 & 0.0 \\
\hline \multirow[t]{3}{*}{ 04:00-24:00 } & Middle & 5.1 & 50.6 & 27.3 & 9.4 & 5.2 & 1.5 & 0.8 \\
\hline & Edge & 2.2 & 52.9 & 29.9 & 10.0 & 3.4 & 1.0 & 0.6 \\
\hline & Corner & 0.0 & 55.7 & 32.8 & 9.4 & 1.0 & 1.0 & 0.0 \\
\hline \multirow[t]{3}{*}{ 06:00-24:00 } & Middle & 4.6 & 45.9 & 30.5 & 10.5 & 5.9 & 1.6 & 0.9 \\
\hline & Edge & 1.9 & 48.0 & 33.4 & 11.2 & 3.7 & 1.2 & 0.6 \\
\hline & Corner & 0.0 & 50.6 & 36.6 & 10.5 & 1.2 & 1.2 & 0.0 \\
\hline
\end{tabular}

variation is close to $20{ }^{\circ} \mathrm{C}$ and the amplitude of track slab temperature variation is close to $10{ }^{\circ} \mathrm{C}$. The amplitude of track slab temperature variation rises with that of the surface air, which indicates that the track slab temperature variation has a great correlation with the change of the surface air temperature, as shown in Fig. 9. The amplitudes of temperature variation from more to less are in the order of the edge, the corner, and the middle area.

A fitting formula is given as follows:

$\Delta T_{\text {slab,daily }}=K \Delta T_{\text {surfaceair,daily }}$,

where $\Delta T_{\text {slab,daily }}$ and $\Delta T_{\text {surface air,daily are track slab and }}$ surface air temperature variations, respectively $\left({ }^{\circ} \mathrm{C}\right)$, and $K$ is the scale factor. For this test, which was taken in an outdoor environment in Chengdu, the scale factor $K$ for the middle, edge, and corner areas are $0.275,0.307$, and 0.419 , respectively; and the goodness of fit of the formula for the above three areas are $0.859,0.877$, and 0.862 , respectively.

\section{Conclusion and recommendation}

This test was taken in Chengdu outdoor environment and has a significant meaning of pinpointing the correlation between the environmental temperature and providing a statistical method for analysis of track slab's temperature load.

A bi-block track slab model was constructed, and the temperature field of the track slab together with the surface air temperature was recorded and analyzed. Some conclusions can be made as follows, which can provide a reference for slab track design and its long-term service performance study.

(1) Track slab temperature and surface air temperature reveal a periodical phenomenon with a day period, which shows a strong connection between them. The temperature gradient in track slab changes almost simultaneously with the surface air temperature, and

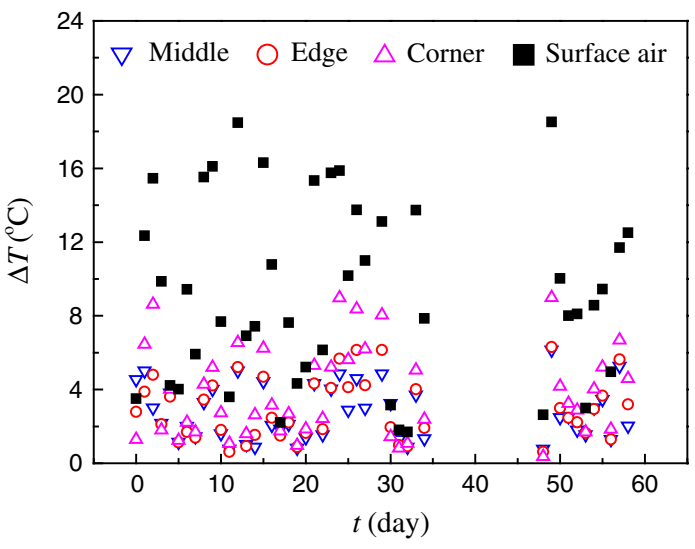

Fig. 8 Distribution of temperature variation amplitude

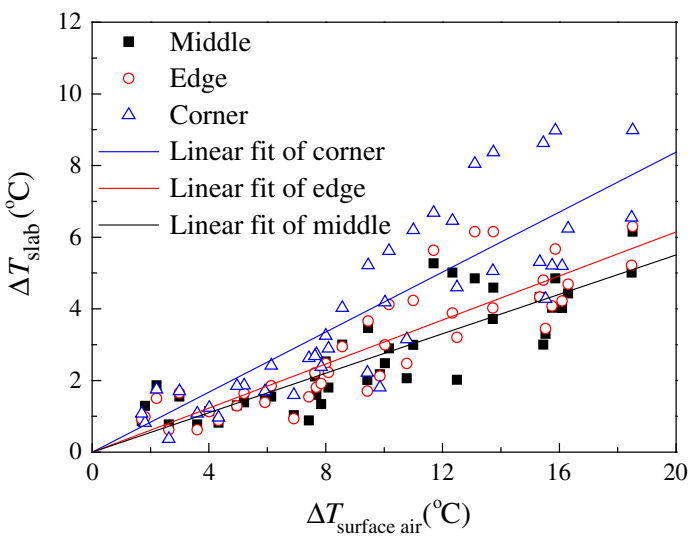

Fig. 9 Relationship between temperature variation of track slab and surface air

shows a clear nonlinearity along the height direction. The temperature gradient in top part is larger than that in the bottom part.

(2) The frequency account analysis shows that the temperature gradient distribution is extremely uneven. The most frequently occurring temperature 
gradient of the track slab is around $-3.5^{\circ} \mathrm{C} / \mathrm{m}$. In more than $75 \%$ period of a day, the temperature gradient is located in the level -10 to $10^{\circ} \mathrm{C} / \mathrm{m}$. The concrete part with a better heat exchange condition with the surrounding air (e.g., the corner part of the slab track) has a narrower band distribution.

(3) At present, due to the fact that there is no traffic or low traffic during the "window" period, the data for frequency distribution histogram should exclude the time zone from 00:00 to 06:00, or should be adjusted according to the real "window" time when we do the coupling fatigue analysis of track slab under train load and temperature gradient.

(4) The amplitude of track slab temperature variation is obviously lower than that of the air temperature variation, and there is a proportionality between them. Because of the differences of heat transfer conditions, the results of the test are different: The amplitudes of temperature variation from more to less are in the order of the edge, the corner, and the middle area.

(5) Limited by the test conditions, only a 2-month-long test was carried out. More tests should be done using this method to get more precise coefficient and convincing conclusion.

Acknowledgments This work was supported by the National Key Basic Research Program of China (973 Program) (2013CB036202), the National Natural Science Foundation of China (51008258), and Fundamental Research Funds for the Central Universities (SWJTU12CX065).

Open Access This article is distributed under the terms of the Creative Commons Attribution License which permits any use, distribution, and reproduction in any medium, provided the original author(s) and the source are credited.

\section{References}

1. He HW (2006) The ballastless track technology. China Railway Publishing House, Beijing (in Chinese)

2. Liu XY, Zhao PR, Yang RS et al (2010) The design theory and method for ballastless track of passenger dedicated railway line. Southwest Jiaotong University Press, Chengdu (in Chinese)

3. Zhao PR, Liu XY (2008) The temperature-stress calculation method and parameter analysis of continuous track slab. Railw Eng 11:81-85 (in Chinese)

4. Cong ZH, Zheng NX, Jin Y (2012) Temperature field division at Liupanshan area of Ningxia for asphalt pavement performance. Adv Mater Res 511:12-15

5. Zhimin T, Zhengjun M, Zou X (2013) Pavement temperature estimation model based on field temperature data. Tongji Daxue Xuebao/J Tongji Univ 41:700-704 (in Chinese)

6. Haigui K, Yuanxun Z, Yingchun C, Ya L (2007) Regression analysis of actual measurement of temperature field distribution rules of asphalt pavement. Chin J Highw Transp 20(6):13-18

7. Rostásy FS, Budelmann H (2007) Verification of thermal restraint of a railways trough structure by long-term monitoring. Struct Infrastruct Eng 3(3):237-244

8. Shao P, Li H, Wu S, Wang T, Liu Z, Li H (2013) Measurement and research on temperature warping of CRTS I track slab and crack between track slab and cement asphalt mortar cushion. Zhongguo Tiedao Kexue 34(2):18-22

9. Zhao C, Song X, Zhu X (2013) Temperature deformation analysis of CRTS II ballastless slab track. In 2013 joint rail conference (pp. V001T01A016-V001T01A016). American Society of Mechanical Engineers

10. Wang SR, Sun L, Li Q (2009) Temperature measurement and temperature stress analysis of ballastless track slab. J Railw Eng Soc 2:52-55

11. Coleri E, Popescu L, Signore JM, Wu R, Harvey JT (2012) PCC slab temperature gradients as a function of structure and environment experience from the SHRP II R21 composite pavement test track. In: 10th international conference on concrete pavements

12. Yang S (1996) A temperature prediction model in new concrete pavement and a new test method for concrete fracture parameters. Doctoral dissertation, Texas A\&M University 